\title{
MOBILE LEARNING NO ENSINO SUPERIOR: uma cartografia a partir das percepções dos docentes
}

\author{
Perla Maria Berwanger \\ João Batista Bottentuit Junior
}

Resumo

Esta investigação aborda a presença e o uso de tecnologias digitais móveis em processos de ensinoaprendizagem. A pesquisa teve como objetivo investigar o uso do smartphone no curso de Administração da UFMA, assim como analisar as motivações dos docentes e discentes em situação de uso dos aplicativos digitais. A investigação, de natureza exploratória-descritiva, adotou uma abordagem mista - quantitativa e qualitativa. O universo da pesquisa foi composto por 61 alunos. Foram utilizados: diário de pesquisa, fichas de observação, questionários fechados de múltipla escolha e questionários mistos. Os resultados indicam que os sujeitos participantes da pesquisa não utilizam smartphones e aplicativos digitais como recurso didático-pedagógico central em sala de aula.

Palavras-chave: mobile learning; smartphone; aplicativos; avaliação da aprendizagem; educação superior.

\section{MOBILE LEARNING IN HIGHER EDUCATION:} cartography based on professors 'perceptions

\section{Abstract}

This research addresses whether or not there is the use of mobile digital technologies in teaching-learning processes in the context of a bachelor's business administration course at the Federal University of Maranhão, Brazil. It aims at examining the use of smartphones, as well as at exploring professors' and students' motivations for the use of digital applications. This exploratory-descriptive research adopted a mixed-method approach, using both qualitative and quantitative data, namely through research diaries, observation notes, and open and closed questions questionnaires applied with 61 students. Findings point out to the fact that the individuals analyzed do not recur to smartphones or digital applications as a crucial didactic-pedagogical source in the classroom.

Keywords: mobile learning; smartphone; applications; learning assessment; higher education.

\section{APRENDIZAJE MÓVIL EN LA EDUCACIÓN SUPERIOR: una cartografía desde las percepciones de los profesores}

\section{Resumen}

Esta investigación aborda la presencia y el uso de tecnologías digitales móviles en los procesos de enseñanza-aprendizaje. La investigación tuvo como objetivo investigar el uso de teléfonos inteligentes en el curso de Administración de la UFMA, así como analizar las motivaciones de maestros y estudiantes en situaciones de uso y sus propósitos a través de aplicaciones digitales. La investigación exploratoria descriptiva adoptó un enfoque mixto: cuantitativo y cualitativo. El universo de investigación estuvo compuesto por 61 estudiantes. Utilizamos un diario de investigación, hojas de observación, cuestionarios cerrados de opción múltiple y cuestionarios mixtos. Los resultados indican que los sujetos que participan en la investigación no usan teléfonos inteligentes y aplicaciones digitales como un recurso didácticopedagógico central en el aula.

Palabras clave: aprendizaje móvil; smartphone aplicaciones; evaluación de aprendizaje; educación universitaria. 


\section{INTRODUÇÃO}

A pesquisa realizada foi ancorada na compreensão de que constantes inovações em tecnologias móveis digitais vêm possibilitando transformações no modo de vida de diversos sujeitos sociais, em contextos particulares e distintos no Brasil. Conforme foi apresentado no relatório da Organização das Nações Unidas para a Educação, a Ciência e a Cultura (UNESCO, 2008), a utilização de dispositivos móveis e de seus softwares e aplicativos associados se propagou na vida cotidiana do brasileiro, chegando aos ambientes de ensino formal. Atuar nesse cenário passou a ser um desafio técnico e metodológico enfrentado por docentes e discentes, em especial quando relacionado ao desenvolvimento, à participação e à colaboração com as reflexões coletivas sobre os processos de aprendizagem em ambientes educacionais (COUTINHO, 2011).

Dessa forma, o diálogo entre "quem ensina" e "quem aprende" passou a ser alterado a partir da incidência e da mediação dessas tecnologias. Observando por esse prisma, notamos que as relações sociais estariam sendo, cada vez mais, impactadas pelas transformações do volume e do fluxo de informação disponível na rede Internet, espaço singular de operação das Tecnologias da Informação e Comunicação (SANTAELLA, 2013a), e pela inserção no sistema de ensino de uma geração de alunos culturalmente digitais, oriundos da sociedade em rede (CASTELLS, 2002). Esses alunos exigem direta e indiretamente das instituições de educação a integração das Tecnologias da Informação e Comunicação (TIC) às práticas do processo de sua formação.

Diversos sujeitos que atuam no ambiente escolar estariam presenciando o possível surgimento de um novo paradigma na educação (SANTAELLA, 2013b). O uso mais intenso de dispositivos digitais móveis, como o smartphone equipamento que reúne os recursos de portabilidade, conectividade, comunicabilidade e ubiquidade, seria um dos fatores importantes na virada do século XX para o XXI, capaz de mudar, de forma rápida e silenciosa, as práticas de aprendizagem e de comunicação em diversos contextos de interação social.

Diante dessa premissa, perguntamo-nos: como as tecnologias digitais móveis são utilizadas nos processos de ensino-aprendizagem do curso de graduação em Administração da UFMA?

Quanto ao objetivo geral desta pesquisa, temos: analisar o uso das tecnologias digitais móveis, especificamente do smartphone, nos processos de ensino-aprendizagem do curso de Administração da UFMA.

Este artigo tem início com uma breve descrição do conceito de mobile learning, seguida de uma apresentação dos aplicativos utilizados nas experiências e dos resultados obtidos por meio das experiências com os docentes do curso de administração da Universidade Federal do Maranhão.

\section{MOBILE LEARNING}

A perspectiva descortinada por George Siemens (2004), que traz uma abordagem conectivista sobre a experiência de aprendizagem vivida nas sociedades do início do século XXI, reforçou o interesse de alguns pesquisadores em compreender quais alternativas pedagógicas poderiam colaborar para atender a algumas necessidades relacionadas aos complexos desafios contemporâneos.

Uma parte dos debates acadêmicos se ocupa da questão do uso de smartphones, aplicativos e outros recursos das tecnologias digitais móveis como possibilidades de ativação das TIC nos processos educativos. Esse uso poderia gerar uma sintonia entre as instituições educacionais e os 
novos contextos de aprendizagem. Nessa perspectiva, a aprendizagem é compreendida como processo cooperativo, interativo e viável também no ciberespaço (SILVA; BERWANGER; BOTTENTUIT JUNIOR, 2018), reflexão compatívelcom a proposição de Gomes (2016), para quem as comunidades de aprendizagem surgem em decorrência das conexões em redes. Essas comunidades se tornam um importante espaço para a construção de conhecimentos e ampliação de saberes. Para Gomes, é necessário que estejamos atentos à criação de estratégias e à construção de sociabilidades em uma contemporaneidade fluída e cambiante.

Contudo, embora as tecnologias digitais móveis estejam cada dia mais presentes em nosso cotidiano, como aponta os relatórios da TELECO (2017), We are Social e HotSuit (2017,2018), da UNESCO $(2016,2017)$, entre outros, ainda avançamos pouco nas investigações sobre os usos e aplicações dessas ferramentas em sala de aula. Ainda não preparamos os sujeitos (docentes e discentes) para aproveitar seu potencial nos processos pedagógicos, incluindo a imersão em metodologias ativas relacionadas à nova abordagem do mobile learning.

O conceito de mobile learning nasce no bojo do desenvolvimento das tecnologias móveis e digitais, a partir de uma linha de investigação relevante para o ambiente informacional da aprendizagem humana (MOURA, 2010). Sobre isso, Crompton (2013, p. 3) menciona que, no mês de janeiro de 2005, Laouris e Eteokleous disseram receber 1.240 itens de resposta ao pesquisar no Google os termos "+” "celular aprendizagem" "+" "definição". Os autores salientam que refizeram a mesma pesquisa em junho do mesmo ano 2005 e o Google forneceu 22.700 itens.

Diante desse fato, Crompton (2013) argumenta que o mobile learning se tornou um termo reconhecido entre estudiosos da temática e, desde então, vários debates estão sendo modelados a fim de entender as particularidades que devem ser incluídas com o propósito de se aproximar de uma conceituação o termo mobile learning / m-learning. A seguir, apresentaremos algumas definições formuladas por estudiosos dessa temática.

O’Malley e outros (2003) definiram m-learning como qualquer tipo de aprendizagem que acontece quando o aluno não está em uma localização fixa ou predeterminada, ou, ainda, quando esse aluno aprende aproveitando oportunidades oferecidas pelas tecnologias móveis. Essa definição coloca o foco do mobile learning, inicialmente, em processos amparados pelo uso de tecnologias que possam ser utilizadas em movimento.

$\mathrm{Na}$ reflexão apresentada por Moura (2009), os pesquisadores ressaltam que esses novos nichos de aprendizagem permitem que pessoas de todas as idades continuem a aprender à sua maneira e conforme à sua disponibilidade de tempo. Observa também que, em uma perspectiva pedagógica, a combinação de tecnologias e estratégias inovadoras facilita o desenvolvimento de novas experiências de aprendizagem direcionadas às necessidades dos aprendizes (MOURA, 2009).

O m-learning ou mobile learning se desenvolveu através do uso de dispositivos digitais móveis conectados à Internet por discentes e docentes em ambientes de aprendizagem à distância (SANTAELLA, 2013a; NEVES, 2007). Na tradução para a nossa língua materna, o termo mobile learning ainda pode ser entendido como a integração de dispositivos móveis no contexto da educação. Quando nos referimos aos dispositivos móveis, estamos falando de um conjunto de aparatos tecnológicos, como smartphones, tablets, ipads e/ou qualquer outro equipamento que funciona enquanto nosso corpo se movimenta.

Em sua tese, Moura (2010) destaca que as principais características do m-learning são a portabilidade dos dispositivos e a mobilidade dos sujeitos, que podem estar física e geograficamente separados uns dos outros, ou em espaços físicos formais de educação, como a sala de aula. 
Os pesquisadores declaram que ainda estão tentando definir um referencial teórico que possa ser aplicado ao m-learning. No entanto, essa definição exige um olhar atento às características específicas dos dispositivos em uso, ao contexto em que esses discentes estão inseridos e às estratégias de aprendizagem utilizadas pelo docente. A Figura 1 apresenta a tríade do mobile learning.

Figura 1: Tríade do mobile learning

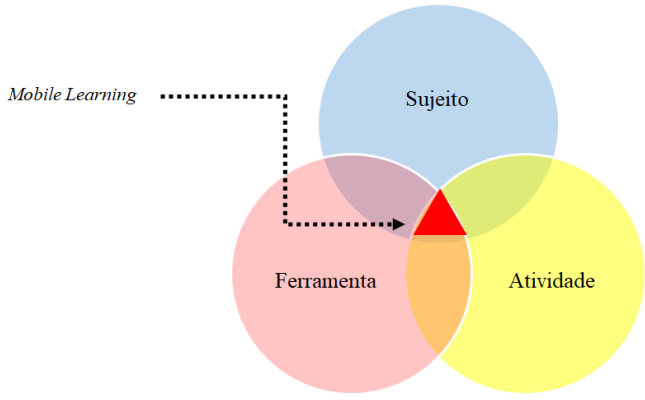

Fonte: desenvolvido pelos autores, baseada no conceito de Moura (2010).

No pensamento de Moura (2010), para que ocorra mobile learning é necessário que haja a interseção de três elementos, como mostra a Figura 1: discente (sujeito), atividade (objeto) e ferramenta (artefato de mediação). Essa interdependência de elementos tornaria possível o mobile learning como metodologia.

Saccol, Schlemmer e Barbosa (2011) explicam que mobile learning são processos de aprendizagem apoiados pelo uso de tecnologias, móveis e sem fio, da informação ou comunicação. Sua principal característica é a mobilidade dos aprendizes. Estes podem estar distantes uns dos outros e/ou em espaços formais de educação, como salas de aula, salas de formação, capacitação e treinamento, ou, até mesmo, local de trabalho.

Já Hashemie outros (2011) referiram-se ao termo mobile learning como a exploração de tecnologias portáteis onipresentes em conjunto com as redes de telefonia sem fio e móveis, objetivando facilitar, apoiar, melhorar e ampliar o alcance do ensino e da aprendizagem.

Anteriormente, Sharples e outros (2006) já haviam definido m-learning como um processo de aprendizagem por meio de conversas, de múltiplos contextos entre pessoas e com o uso de tecnologias interativas. Essa definição inclui quatro constructos do m-learning, conforme representado pela Figura 2.

Figura 2: Os quatro constructos de m-learning de Sharples et al. (2006)

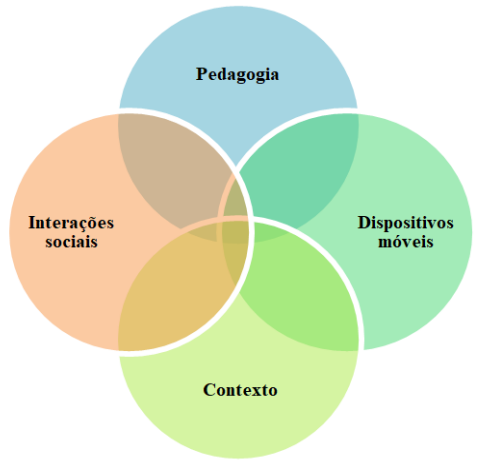

Fonte: inspirados em Sharples et al. (2006). 
Essa abordagem já incluía o mobile learning de um modo diferente das definições que a antecederam, nas quais o centro era o aparato tecnológico físico. Em Sharples e outros (2006), mobile learning é um aprendizado em contextos variados, que usa como intermédio as interações sociais e de conteúdos proporcionados pela mediação e uso de dispositivos eletrônicos pessoais. Essa definição foi apresentada por esses autores em artigo sobrea teoria da conversação.

Em 2013, a pesquisadora Helen Crompton, apoiada na extensão dos estudos de Sharples, fez modificações na definição apresentada por Sharples e outros em 2006. O novo conceito apresentado inclui as quatro construções centrais no m-learning de Sharples. No entanto, o texto foi reeditado para reduzir possíveis duplos sentidos, com reforço na pontuação, a fim de proporcionar maior clareza. Dessa forma, o m-learning é o "[...] aprender em múltiplos contextos, por meio de interações sociais e de conteúdo, usando dispositivos eletrônicos pessoais" (CROPMTON, 2013, p. 78). Os pesquisadores explicam que o "contexto" pode ser de dois tipos: o consciente e o neutro.

a) Aprendizado em contexto consciente é aquele que pode acontecer em ambiente acadêmico ou não acadêmico; aqui o ambiente físico pode ou não estar envolvido na experiência de aprendizagem.

b) Aprendizado em contexto neutro é aquele que pode ocorrer de duas formas: a primeira, quando o ambiente pode ser parte da experiência de aprendizagem (por exemplo, códigos de digitalização para obter mais informações sobre uma exposição em um museu); a segunda, quando o ambiente tem um papel neutro na experiência de aprendizagem, por exemplo, leitura de artigos da Web enquanto viaja de ônibus, carro, trem etc.

Podemos entender, a partir dessas reflexões, que mobile learning pode ser um processo dirigido por si ou por outros, seja em contexto de participação em uma aula formal, em um ambiente escolar/acadêmico com uso dos dispositivos móveis, seja em uma experiência de aprendizagem espontânea e não planejada, como usar o dispositivo para procurar informações sobre algo que acabou de provocar interesse. Tudo isso acontece enquanto esse sujeito se desloca de um ponto físico a outro, a pé, dentro de um ônibus, de um carro, de um trem etc.

Podemos imaginar também o potencial de uso direcionado dessa tecnologia e como ela possibilitaria a diversos sujeitos, em diferentes contextos, a experiência de se relacionar com informações relevantes para atender às suas necessidades, uma vez que a mobilidade proporcionaria a liberdade desses sujeitos em relação ao ambiente formal (ver Tabela 1).

Tabela 1: Perspectivas dos avanços tecnológicos no ensino

\begin{tabular}{|c|l|}
\hline Períodos & \multicolumn{1}{|c|}{ Tecnologia no ensino } \\
\hline $2016 / 17$ & Dispositivos pessoais móveis, learning analytics e aprendizagem adaptativa \\
\hline $2018 / 19$ & Realidade virtual e aumentada, FabLabs - laboratórios maker \\
\hline 2020 & Computação afetiva; Robótica \\
\hline
\end{tabular}

Fonte: adaptado de Moran (2007).

Moran (2007) afirma que seria necessário propor aos docentes umtrabalho em conjunto, de maneira colaborativa, emuma jornada institucional e não individual, para que essas tecnologias assumissem um papel fundamental no processo de aprendizagem ativa no ambiente escolar, permitindo compartilhar e trazer propostas que façam sentido aos discentes. No Quadro 2, 
apresentamos o cenário atual e a projeção de Moran para o desenvolvimento de tecnologias cada vez mais inteligentes, pressupondo pessoas mais ativas.

\section{O PERCURSO METODOLÓGICO}

Para esta pesquisa utilizamos o método da Cartografia. Como método de pesquisa, a cartografia foi, originalmente, pensada por Gilles Deleuze e Félix Guatari (2011), na década de 1960. Para eles, os modelos de pesquisas disponíveis à época, de cunho eminentemente demonstrativos-representacionais, não se adequavam e nem conseguiam dar conta do teor processual do objeto dos seus estudos, que eram processos e produção de subjetividade. Em complemento, Souza e Francisco (2016) afirmam que a cartografia é uma linha de pesquisa que concebe a inseparabilidade entre conhecer e intervir e posiciona pesquisador, pesquisados e objeto em um mesmo plano de convergência. Esse método não se refere a uma escolha a respeito de um posicionamento epistemológico-metodológico, nem traz implicações apenas teóricas, mas, sobretudo, prático-políticas e éticas.

Esta pesquisa também pode ser classificada como exploratória-descritiva, que, para Gil (1991), descreve situações precisas e pretende descobrir as relações existentes entre seus elementos e componentes. Tais estudos objetivam a familiaridade com o fenômeno ou uma nova percepção, além de construir novas ideias sobre ele. Os estudos exploratórios não elaboram hipóteses a serem testadas no trabalho e restringem-se à definição de objetivos e à busca de maiores informações sobre determinado assunto a ser estudado.

O estudo inclui também uma reflexão descritiva, proporcionada pela aproximação entre pesquisador e sujeitos das instituições (docentes). A partir da realização da coleta de dados, da observação não participante e do uso dos aplicativos em dispositivos móveis. Com os participantes do curso de Administração, foi possível identificar e descrever aspectos das relações entre esses sujeitos, protagonistas do processo de ensino-aprendizagem em sala de aula (GIL, 1991). A abordagem adotada para a coleta e tratamento dos dados tem natureza mista (quantitativa/qualitativa).

A coleta de dados nesta pesquisa foi realizada diretamente pelos pesquisadores durante o segundo semestre de 2018. Para tanto, foram utilizados como instrumentos de coleta:

a) Questionário Diagnóstico e Questionário de Pós-teste com os discentes e docentes;

b) Observação não participativa;

c) Diário de Campo.

No próximo tópico apresentamos quais foram os aplicativos utilizados durante a experiência com os participantes do curso de graduação em Administração da UFMA.

\section{Aplicativos utilizados nas experiências mobile learning}

Em nossa experiência no curso de Administração foram utilizados três aplicativos: Kahoot!, GoSoapBox e Edpurzle. A escolha por esses aplicativos se deu diante da necessidade de envolvermos os discentes do curso de Administração da UFMA em um modelo pedagógico ativo e interativo. Carvalho (2015, p. 11) apresenta três eixos principais de intervenção em contexto educativo formativo: sondar e testar, representar o conhecimento e desafiar a aprender.

O primeiro aplicativo utilizado foi o Kahoot! A escolha se deu em razão do recurso da gamificação, uma funcionalidade do aplicativo que possibilita a utilização de Quiæ. Também apresenta outras atividades, como: Jumble, Discussion e Survey. Sua utilização é intuitiva e não há necessidade de instalação prévia nos dispositivos móveis do docente nem dos discentes. 
O segundo aplicativo utilizado foi o GoSoapBox. Este aplicativo não possui o recurso da gamificação, porém tem um conjunto de funcionalidades que podem auxiliar o docente no planejamento e execução de uma atividade de avaliação da aprendizagem, a qual é mediada pelo uso do smartphone. É um aplicativo de uso intuitivo e não necessita de instalação, basta inserir o código gerado pelo sistema para acessar à atividade.

O terceiro aplicativo utilizado pelosdiscentes e docentes do curso de Administração foi o Edpuгzle. Este aplicativo possibilita que os docentes realizem a interatividade através de vídeos. Além da apresentação de conteúdo, é possível que o aplicativo seja utilizado como um verificador de aprendizagem a partir da inserção de perguntas abertas e/ou de múltipla escolha, gravações com explicações ou informação de áudio (voz do professor, se preferido), ou ainda com textos. Nos relatos de experiência foram apresentadas as quatro etapas de coleta, como ilustrado na Tabela 2.

Tabela 2: Etapas de coleta da pesquisa

\begin{tabular}{|c|c|c|c|}
\hline $\mathbf{N}^{o}$ & O quê & Quando & Quem \\
\hline \multirow[b]{2}{*}{ ETAPA I } & \multirow{2}{*}{$\begin{array}{l}\text { Apresentação do Projeto de Pesquisa; } \\
\text { Apresentação de documentação necessária } \\
\text { para coleta de dados (Aceite do CEP; } \\
\text { TCLE, Questionário Diagnóstico e Pós- } \\
\text { teste); } \\
\text { Construção de Cronograma provisório; } \\
\text { Apresentação de aplicativos a serem } \\
\text { utilizados em sala de aula na experiência } \\
\text { com smartphone. }\end{array}$} & 28 agosto & $\begin{array}{l}\text { Pesquisadores e } \\
\text { Docente }\end{array}$ \\
\hline & & 4 setembro & $\begin{array}{l}\text { Pesquisadores e } \\
\text { Docente }\end{array}$ \\
\hline \multirow{2}{*}{ ETAPA II } & $\begin{array}{l}\text { Aplicação do TCLE, Teste Diagnóstico } \\
\text { docente e discentes - Turma de Logística }\end{array}$ & 3 setembro & $\begin{array}{l}\text { Pesquisadores, Docente } \\
\text { e Discentes }\end{array}$ \\
\hline & $\begin{array}{l}\text { Aplicação do TCLE, Teste Diagnóstico } \\
\text { docente e discentes - Turma de TGA }\end{array}$ & 14 setembro & $\begin{array}{l}\text { Pesquisadores, Docente } \\
\text { e Discentes }\end{array}$ \\
\hline \multirow{4}{*}{ ETAPA III } & $\begin{array}{l}\text { Experiência I - uso do Kahoot: - Turma de } \\
\text { Logística }\end{array}$ & 24 setembro & $\begin{array}{l}\text { Pesquisadores, Docente } \\
\text { e Discentes }\end{array}$ \\
\hline & $\begin{array}{l}\text { Experiência II - uso do GoSoapBox- } \\
\text { Turma de TGA }\end{array}$ & 5 outubro & $\begin{array}{l}\text { Pesquisadores, Docente } \\
\text { e Discentes }\end{array}$ \\
\hline & $\begin{array}{l}\text { Experiência III - uso do Edpuzzle - Turma } \\
\text { de Logística }\end{array}$ & 13 novembro & $\begin{array}{l}\text { Pesquisadores, Docente } \\
\text { e Discentes }\end{array}$ \\
\hline & $\begin{array}{l}\text { Experiência IV - uso do Kahoot! - Turma } \\
\text { de TGA }\end{array}$ & 23 novembro & $\begin{array}{l}\text { Pesquisadores, Docente } \\
\text { e Discentes }\end{array}$ \\
\hline \multirow[t]{2}{*}{ ETAPA IV } & $\begin{array}{l}\text { Aplicação dos questionários de Pós-teste } \\
\text { com docente e discentes - Turma de } \\
\text { Logística }\end{array}$ & 13 novembro & $\begin{array}{l}\text { Pesquisadores, Docente } \\
\text { e Discentes }\end{array}$ \\
\hline & $\begin{array}{l}\text { Aplicação dos questionários de Pós-teste } \\
\text { com docente e discentes - turma de TGA }\end{array}$ & 23 novembro & $\begin{array}{l}\text { Pesquisadores, Docente } \\
\text { e Discentes }\end{array}$ \\
\hline
\end{tabular}

Fonte: produzido pelos pesquisadores 
A construção desse cronograma foi uma parceria entre os pesquisadores e os docentes do curso de administração. A partir deste, foi possível realizar modificações/ajustes nos instrumentos, tornando-os mais eficazes na coleta de dados dos sujeitos do curso de Administração da UFMA. As coletas foram realizadas nos meses de agosto, setembro, outubro e novembro de 2018. O processo de coleta foi dividido em quatro etapas distintas, como apresentamos no quadro acima. A divisão das atividades, por etapas, objetivou minimizar o impacto de nossa presença e interferência em quaisquer atividades do calendário regular dos docentes e suas aulas, provas e atividades afins, e, ainda, maximizar cada momento presente dedicado exclusivamente à ação proposta, como será descrito adiante.

\section{RESULTADOS E ANÁLISES: PERCEPÇÕES DOCENTES}

Os dados apresentados nesta seção foram coletados pelos pesquisadores por meio de um conjunto de instrumentos construídos e usados para esta pesquisa. Combinamos diferentes dados para analisar o uso do smartphone nos processos de ensino-aprendizagem. Os resultados são referentes à coleta de dados realizada comos dois docentes das disciplinas deLogística e de TGA, da Universidade Federal do Maranhão. Decidimos chamar os docentes pela identificação de D1 e D2, de modo a salvaguardá-los, mesmo tendo recebido deles a assinatura de participação no Termo de Consentimento Livre e Esclarecido (TCLE).

Foi possível verificar, a partir das respostas, que os dois docentes mostram traços semelhantes, seja na graduação do bacharelado ou na pós-graduação com o curso de mestrado e doutorado. Além disso, ambos fazem parte da instituição de educaçãohámais de três anos e mantêm o vínculo de dedicação exclusiva. Na Tabela 3, apresentamos o perfil pessoal docente.

Tabela 3: Perfil pessoal docente

\begin{tabular}{|l|l|}
\hline Perfil & $\begin{array}{l}\text { O perfil social de D1 e D2 são semelhantes. De acordo com as informações coletadas, } \\
\text { ambos têm formação profissional em bacharelado, mestrado e doutorado. Quanto ao tipo } \\
\text { Pessoal } \\
\text { Docente vínculo profissional com a instituição no curso de Administração na UFMA, ambos } \\
\text { D1 e D2 }\end{array}$ \\
$\begin{array}{l}\text { são docentes do quadro efetivo e trabalham em regime de dedicação exclusiva; D1 está na } \\
\text { instituição há mais de oito anos, enquanto D2 está na instituição há menos de quatro } \\
\text { anos. }\end{array}$
\end{tabular}

Fonte: desenvolvido pelos pesquisadores (2018)

$\mathrm{Na}$ Tabela 4, apresentamos o perfil tecnológico docente. Nessa dimensão buscamos identificar como os docentes faziam uso dos dispositivos digitais móveis, especificamente do smartphone em sala de aula. 
Tabela 4: Perfil Tecnológico Docente

\begin{tabular}{|c|l|}
\hline \multicolumn{1}{|c|}{ Perfil Tecnológico do docente - uso do smartphone em contexto social } \\
\hline \multirow{6}{*}{ D1 } & $\begin{array}{l}\text { Quanto ao perfil tecnológico, o docente D1 disse possuir Internet em sua residência, além } \\
\text { de tecnologias, como notebook, tablet e smartphone. Indagado se conseguia diferir entre um } \\
\text { smartphone e um celular, o docente D1 respondeu que o smartphone acessa a Internet, appp e } \\
\text { semelhantes. Sobre a configuração da conta telefônica que possui, disse possuir a } \\
\text { configuração do plano pós-pago. Quando questionado sobre qual tipo de dispositivo } \\
\text { prefere trabalhar na elaboração de suas aulas e trabalhos acadêmicos, D1 respondeu que } \\
\text { opta pelo uso do notebook; }\end{array}$ \\
\hline \multirow{6}{*}{ D2 } & $\begin{array}{l}\text { Quanto ao perfil tecnológico, o docente D2 disse possuir Internet em sua residência, além } \\
\text { de tecnologias como computador de mesa, notebook, tablet e smartphone. Indagado se } \\
\text { conseguia diferir entre um smartphone e um celular, D2 respondeu que o smartphone tem } \\
\text { acesso à Internet, aplicativos e redes sociais. Sobre a configuração da sua conta telefônica, } \\
\text { respondeu que seu plano de telefonia é pós-pago. Questionado em que tipo de } \\
\text { dispositivo prefere trabalhar na elaboração de suas aulas e trabalhos acadêmicos, D2 } \\
\text { respondeu que utiliza o notebooke o smartphone para entretenimento, como vídeos, música, } \\
\text { jogos, fotos e livros. Além disso, realiza transações bancárias usando o dispositivo móvel. } \\
\text { D2 respondeu que, eventualmente, quando tem uma dúvida sobre a funcionalidade do } \\
\text { aparelho, recorre ao manual do fabricante, pesquisa na Internet como resolver sua } \\
\text { dificuldade e não se incomoda em pedir ajuda a uma pessoa amiga. Disse também que o } \\
\text { tempo médio que dedica ao uso do smartphone é maior que três horas diárias. }\end{array}$ \\
\hline
\end{tabular}

Fonte: desenvolvido pelos pesquisadores (2018).

Quanto ao Perfil Tecnológico dos docentes, quando questionados sobre o uso do smartphone em contexto social, ambos os docentes responderam que não proíbem, mas também não incentivam o uso do smartphone na sala de aula. Ambos identificaram corretamente as diferenças entre celular e smartphone e preferem trabalhar em seus notebooks a qualquer outro equipamento que possuam em casa, como computador de mesa ou tablets. Ambos os docentes eventualmente sentem dificuldade ao utilizarem seus aparelhos smartphone. Para sanar suas dúvidas, recorrem a consultas ao manual do fabricante, vídeos ou amigos. Ficam conectados em média por mais de três horas diárias.

Entendemos que seus dispositivos móveis estão sendo subutilizados academicamente. Esses dados contribuem com os estudos de Carvalho (2015), que alertam sobre a diversidade de aplicativos destinados aos dispositivos móveis, sobre as atividades de buscas feitas sem critério e/ou direcionamento e sobre a importância de fornecer orientações aos discentes acerca de como usar esses dispositivos móveis em contexto educativo.

Esta abordagem se aproxima do pensamento de Aharony (2013), para o autor, os smartphones podem se transformar em tecnologias eficientes e adequadas para executar várias tarefas ao mesmo tempo.

Para Margaryan e outros (2011), o potencial criativo e disruptivo das tecnologias móveis como ferramentas de aprendizagem ainda não aconteceu totalmente. Nesse sentido, o papel do professor é crucial no uso da tecnologia de forma inovadora e na realização de experiências de aprendizagem baseadas em trabalhos de equipe, resolução de problemas da vida real, simulações, jogos educativos e abordagens mais colaborativas e interativas. Até aqui, ficamos à espera de que 
a escola ajude a potencializar o uso dos dispositivos móveis como suporte à aprendizagem. $\mathrm{Na}$ Tabela 5, apresentamos o perfil profissional docente.

\section{Tabela 5: Perfil profissional docente}

\begin{tabular}{|c|c|}
\hline D1 & $\begin{array}{l}\text { Esse docente considera importante o uso de tecnologias digitais móveis em sala de aula, porque } \\
\text { é uma forma de utilizar a mesma linguagem dos alunos e tornar a aula mais dinâmica. Em dias } \\
\text { de avaliação, esse docente respondeu que, enquanto os alunos respondem às suas provas } \\
\text { individualmente, ele aproveita para colocar uma atividade em dia e também "fica de olho" no } \\
\text { comportamento dos discentes durante a prova. Sobre o uso do smartfone em sala de aula, o } \\
\text { docente D1 respondeu que nunca utiliza o dispositivo como ferramenta de apoio para a } \\
\text { exposição do conteúdo da disciplina que ministra no curso de Administração. Respondeu ainda } \\
\text { que não proíbe e, também, não incentiva o uso desses dispositivos em sala de aula por falta de } \\
\text { planejamento pessoal. Acrescentou que, além de não proibir, tenta gerenciar o uso. Afirma que } \\
\text { a proibição tem um efeito contrário ao que se planeja. Quando permite o uso de dispositivos } \\
\text { móveis em sala de aula, ele é feito em pesquisas e em outros exemplos de casos práticos que } \\
\text { envolvem o conteúdo como ferramenta complementar ao conteúdo apresentado por ele. O } \\
\text { docente D1 disse que acredita que o uso do smartfone em sala de aula ajuda e ainda pode motivar } \\
\text { a participação dos discentes durante a aula. Mesmo acreditando nessa possibilidade, afirmou } \\
\text { que a utilização do smartphone é feita duas vezes por semestre para realizar busca e leitura de } \\
\text { artigos científicos. Sobre o uso e posse das TIC em sala de aula, o docente D1 respondeu que o } \\
\text { notebooke é de posse particular, enquanto o datashow é de posse institucional. Seu uso se dá } \\
\text { mediante solicitação no centro administrativo Paulo Freire. Pedimos para esse mesmo docente } \\
\text { D1 nos descrever uma experiência realizada no curso de Administração, utilizando os recursos } \\
\text { oferecidos pelas tecnologias da comunicação e informação. Ele respondeu que faz uso do } \\
\text { smartphone para pesquisar artigos e outras leituras no portal de periódicos CAPES. Disse que } \\
\text { gostaria de utilizar aplicativos para avaliação de aprendizagem, como o Kaboot. }\end{array}$ \\
\hline D2 & $\begin{array}{l}\text { Esse docente considera importante a utilização de tecnologias digitais móveis em sala de aula, } \\
\text { porque facilita o ensino e aprendizagem, além de estar em consonância com o contexto atual de } \\
\text { educação. Em dias de avaliação, esse docente aproveita para colocar alguma atividade em dia, } \\
\text { sem tirar o olho dos seus discentes enquanto eles respondem às questões das provas. } \\
\text { Indagamos se costuma utilizar o smartphone como ferramenta de apoio para a exposição de } \\
\text { conteúdo e a resposta obtida foi que nunca faz uso do smartphone para essa finalidade, mas, } \\
\text { durante sua exposição de conteúdo, não proíbe e, também, não incentiva que os discentes o } \\
\text { utilizem em sala de aula. O docente D2 acredita que o uso correto do smartfone em sala de aula } \\
\text { como ferramenta de auxílio de aprendizado tem benefícios. Atribui que um dos problemas } \\
\text { nesse uso é a maturidade dos alunos para compreender e fazer um uso correto do smartphone } \\
\text { como ferramenta. O docente disse que faz uso de alguns aplicativos como suporte ao } \\
\text { aprendizado, mas nunca conseguiu utilizá-los em sala de aula. Já fez uso de aplicativos em } \\
\text { atividades para serem resolvidas em casa, mas nem mesmo essas envolveram o uso do } \\
\text { smartphone. Questionamos esse docente sobre a utilização das TIC em sala de aula, se são de } \\
\text { propriedade particular ou da instituição. Ele respondeu que são aplicativos disponíveis } \\
\text { gratuitamente na Internet. Quando pedimos ao docente D2 para descrever brevemente uma } \\
\text { experiência que realiza ou realizou em suas aulas com seus discentes no curso de } \\
\text { Administração, ele respondeu que fez/faz uso do aplicativo utilizado para construção de mapas } \\
\text { mentais. Esse docente descreveu uma experiência realizada chamada de Game Revisão. Essa } \\
\text { atividade ocorre como uma revisão de conteúdo antes das avaliações, objetivando a fixação do } \\
\text { conteúdo. }\end{array}$ \\
\hline
\end{tabular}

Fonte: desenvolvido pelos pesquisadores (2018). 
Sobre o perfil profissional no contexto da expertise docente, destacamos que ambos os docentes não fazem uso do smartphone em sala de aula. Mesmo em dias de avaliação, eles preferem usar o tempo disponível para colocar em dia alguma tarefa e se manterem vigilantes quanto ao "passeio" dos discentes na web e/ou redes sociais. Não costumam proibir, mas também não foi dito que há incentivo sobre o uso desses dispositivos em sala de aula.

Percebemos que ainda há uma dúvida e/ou redução do conceito e uso das TIC e tecnologias digitais móveis, como nos lembram Saccol e Reinhard (2007). Os autores afirmam que o uso das ferramentas figura entre os principais temas discutidos na área empresarial e/ou acadêmica. No entanto, por serem considerados relativamente recentes, ainda há em torno deles certa confusão conceitual. Os docentes participantes acreditam que o bom uso do dispositivo pode auxiliá-los com o conteúdo e promover diálogos e formas de aprendizagem. Um dos docentes manifestou o desejo de utilizar futuramente os aplicativos e smartphones em suas aulas.

Nesse sentido, Belloni e Bévort (2009) afirmam que alguns fatores contextuais podem incidir diretamente na inserção de tecnologias digitais móveis em práticas educativas. Entre esses fatores, os autores destacam: a formação inicial precária de professores diante do uso dessas ferramentas na educação; a falta de tempo para realizar formação continuada; e os problemas técnicos e operacionais com os recursos tecnológicos presentes nas instituições escolares, como a escassez de verbas para mantê-los em funcionamento.

\section{CONSIDERAÇÕES FINAIS}

Acreditamos que esta pesquisa contribuiu com as reflexões sobre mobile learning a partir da perspectiva dos resultados no curso de graduação em Administração da UFMA. Os resultados foram obtidos através das experiências realizadas com o uso do smartphone e de tecnologias digitais móveis em sala de aula.

Ao nos aproximarmos de conceitos e reflexões de diversos autores sobre o mobile learning, bem como das experiências realizadas e vivenciadas durante o segundo semestre de 2018 no curso de Administração da UFMA, aprendemos que a adesão do uso de tecnologias digitais móveis em sala de aula pode facilitar, e até potencializar, em médio prazo, os processos de ensino-aprendizagem não somente nesse curso, mas em qualquer outra área de educação formativa.

No entanto, é necessário empatia com a cultura digital e desprendimento do ensino tradicional. Esse é um processo de construção contínua entre docentes e discentes, pois envolve uma variedade de recursos que convergem em um único dispositivo (smartphone) e que podem tornar o processo de aprendizagem mais lúdico e prazeroso a todos os envolvidos (CARVALHO, 2015). A sua apropriação deve se efetivar de forma planejada e coordenada com os processos de sensibilização e formação docente e discente.

Quanto à pergunta norteadora desta investigação - como as tecnologias digitais móveis são utilizadas nos processos de ensino-aprendizagem no curso de graduação em Administração na UFMA? constatamos, por meio da coleta de dados realizada com os sujeitos participantes, que não havia uso de tecnologias digitais móveis no curso de Administração. Naquele contexto formal de ensino, mesmo que os docentes não façam a proibição do uso de smartphones, não há o incentivo declarado ao seu uso durante as aulas.

Conseguimos responder ao objetivo geral da pesquisa, que foi analisar o uso do smartphone nos processos de ensino-aprendizagem do curso de Administração da UFMA. A partir das interpretações das respostas e das observações não participantes, realizadas durante o período de coleta de dados 
em campo, podemos afirmar que docentes e discentes não utilizam o smartphone nos processos de ensino-aprendizagem no curso de Administração da UFMA.

Com o questionário de pós-teste docente, obtivemos algumas respostas que poderiam justificar essa postura: ausência de competências técnicas (formação docente) para operar as metodologias ativas, capazes de reposicionar esses sujeitos em sala de aula; fragilidade estrutural da rede sem fio, pois o prédio possui Internet sem fio, porém, em algumas salas, o sinal wi-fi não chega, nem mesmo o sinal das operadoras de telefonia móvel; dispositivos com tecnologia defasada em posse dos discentes, pois nem todos os aparelhos têm memória suficiente ou disponível, ou, ainda, sua versão de atualização não é mais compatível com algumas tecnologias digitais móveis.

Percebemos que, de modo geral, os docentes do curso de Administração fazem uso de algumas TIC, como projetor multimídia enotebook, durante suas aulas. Eles as usam principalmente como ferramentas de apoio à comunicação e à exposição oral. As TIC são utilizadas para facilitar a apresentação de um conteúdo, gerir o aprendizado e comunicar informações que julguem necessárias/importantes de serem compartilhadas. Entendemos que o uso desse conjunto de ferramentas das TIC pode ser mais explorado para promover outras formas e possibilidades de incrementar e favorecer o aprendizado em sala de aula. Esta perspectiva nos leva a acreditar que ainda existem espaços e oportunidades para o emprego de TDM em sala de aula (SOSTER, 2011).

Verificamos com os docentes que o uso do smartphone e dos aplicativos Kahoot! Go SoapBox e Edpuzzle trouxe modificações positivas e/ou negativas durante o processo de ensino aprendizagem. Podemos afirmar que, ao trabalhar de forma pedagógica com o smartphone e com os aplicativos Kahoot! Go SoapBox e Edpuzそle, percebemos reações positivas e, também, negativas durante a experiência nos processos de ensino-aprendizagem com estas tecnologias.

Os aspectos considerados positivos estão relacionados à inovação metodológica, à motivação entre os membros da turma e, também, às possibilidades de usar esse conjunto de tecnologias em outros âmbitos, como no ambiente de negócios das organizações.

Sugerimos a ampliação do escopo do campo empírico, realizandoum estudo comparativo entre instituições de ensino superior do estado do Maranhão. Outro caminho para ampliar as reflexões é o teste de outros tipos de aplicativos. Nesta pesquisa, optamos por propor e observar experiências baseadas napercepção do docentesobreo uso de aplicativos, mas podemos explorar também a percepção dos discentes.

\section{REFERÊNCIAS}

AHARONY, Noa. Librarians \& apps; attitudes towards mobile services. Aslib Proceedings, v. 65, n. 4, p. 358-375, 2013. Disponível em http://dx.doi.org/10.1108/ap-07-2012-0059. Acesso em 29 nov. 2018.

BELLONI, Maria Luisa; BÉVORT, Evelyne. Mídia-educação: conceitos, história e perspectivas. Educ. Soc., Campinas, v. 30, n. 109, p. 1081-1102, set./dez. 2009. Disponível em http://www.cedes.unicamp.br. Acesso em 27 nov. 2018.

CARVALHO, Ana Amélia Apps para ensinar e para aprender na era mobile-learning. In: CARVALHO, Ana Amélia (coord.). Apps para dispositivos móveis: manual para professores, formadores e bibliotecários. Lisboa: República Portuguesa, 2015.

CASTELLS, Manuel. A era da informação: economia, sociedade e cultura. A sociedade em rede. v. 1. São Paulo: Paz e Terra, 2002. 
COUTINHO, Clara Pereira. Metodologia de Investigạ̧ão em Ciências Sociais e Humanas: teoria e prática. Coimbra: Almedina, 2011.

CROMPTON, Helen. A historical overview of mobile learning: Toward learner-centered education. Handbook of mobile learning. New York: Routledge, 2013. p. 3-14. Disponível em https://www.researchgate.net/publication/263852116/download. Acesso em 2 jan. 2020.

DELEUZE, Gilles; GUATARRI, Félix. Mil platôs. 34. ed. Rio de Janeiro: Letras, 2011.

GIL, Antonio Carlos. Como elaborar projetos de pesquisa. 4. ed. São Paulo: Atlas, 1991.

GOMES Conceição Malhó. Práticas de mobile learning: desenvolvimento de competências básicas da disciplina de inglês através da Plataforma Educativa Edmodo. In: Atas do 3. ${ }^{\circ}$ Encontro sobre Jogos e mobile learning. Universidade de Coimbra, Faculdade de Psicologia e de Ciências da Educação, LabTE, 2016.

GOMES, Maria Gisélia da Silva. Celular e estudante: uso do dispositivo móvel dentro da escola. 136f. Dissertação (Mestrado) Educação. Universidade Federal de Alagoas, Alagoas, 2018.

HASHEMIA, Masoud; AZIZINEZHAD, Masoud; NAJAFIA, Vahid; NESARI, Ali Jamali. What is mobile learning? Challenges and capabilities. Procedia, Social and Behavioral Sciences, [New York], v. 30, p. 2477-2481, 2011. Disponível em https://core.ac.uk/download/pdf/82667514.pdf. Acesso em 29 fev. 2020.

MARGARYAN, Anoush; LITTLEJOHN, Allisom; VOJT, Gabrielle. Are digital natives a myth or reality? University students' use of digital technologies. Computers and Education, v. 56, p. 429440, 2011.

MORAN, José Manuel A educação que desejamos: novos desafios e como chegar lá. Campinas: Papirus Ed., 2007.

MOURA, Adelina Maria Carreiro. Geração móvel: um ambiente de aprendizagem suportado por tecnologias móveis para a "Geração Polegar", 2009. Disponível em http://adelinamouravitae.com.sapo.pt/gpolegar.pdf. Acesso em 14 jan. 2020.

MOURA, Adelina Maria Carreiro. Apropriação do telemóvel como ferramenta de mediação em mobile learning: estudos de caso em contexto educativo. 630 f. Tese (Doutorado), Ciências da Educação, Instituto de Educação, Universidade do Minho, Braga, 2010.

NEVES, Marcio. M-learning - a evolução do acesso ao aprendizado, 2007. Disponível em http://portal.webaula.com.br/noticia.aspx?sm=noticias\&codnoticia=664. Acesso em 14 jan. 2020.

O'MALLEY, Giasemi Vavoula. MOBI learn WP4 - Diretrizes para aprendizagem / ensino / tutoria em um ambiente móvel, 2003.2 Disponível em http://www.mobilearn.org/download/results/guidelines. Acesso em 18 set. 2019.

ORGANIZAÇÃO PARA COOPERAÇÃO E DESENVOLVIMENTO ECONÔMICO. Estudos da OCDE sobre competências: competências para o progresso social: o poder das competências socioemocionais. São Paulo: Fundação Santillana, 2015.

SACCOL, Amarolinda Zanela; SCHLEMMER, Eliane; BARBOSA, Jorge. M-learning e u-learning: novas perspectivas das aprendizagens móvel e ubíqua. São Paulo: Pearson Prentice Hall, 2011. Disponível em http://dx.doi.org/10.1590/S1415-65552007000400009. Acesso em 28 fev. 2019.

SACCOL, Amarolinda Zanela; REINHARD, Nicolau. Tecnologias de informação móveis, sem fio e ubíquas: definições, estado-da-arte e oportunidades de pesquisa. Rev. adm. contemp., Curitiba, v. 11, n. 4, out./dez. 2007. Disponível em http://dx.doi.org/10.1590/S141565552007000400009. Acesso em 28 fev. 2010. 
SOSTER, Tatiana Sansone $O$ uso da tecnologia da informação e comunicação no processo de ensino e aprendizagem: estudo de um curso superior na área de administração. 133f. Dissertação (Mestrado) Administração de Empresas. Escola de Administração de Empresas de São Paulo, Fundação Getúlio Vargas, São Paulo, 2011.

SANTAELLA, Lúcia. Comunicação ubiqua: repercussões na cultura e na educação. São Paulo: Paulus, 2013a. (Coleção Comunicação).

SANTAELLA, Lúcia. Desafios da ubiquidade para a educação. Revista Ensino Superior UNICAMP, Campinas, v. 10, n. 4, s. p., abr. 2013b.

SHARPLES, Mike; TAYLOR, Josie; VAVOULA, Giasemi. Theory of Learning for the Mobile Age. In: ANDREWS, Richard; HAYTHORNTWAITE, Caroline (orgs.). The Sage Handbook of Elearning Research. Thousand Oaks, CA: Sage Publications, 2006. Disponível em https://telearn.archives-

ouvertes.fr/file/index/docid/190276/filename/Sharples et al Theory of Mobile Learning pr eprint.pdf. Acesso em 13 jan. 2020.

SIEMENS, George. Connectivism: a learning theory for the digital age. 2004.

SILVA, Elizabeth; BERWANGER, Perla Maria; BOTTENTUIT JUNIOR, João Batista. Uso de Redes Sociais na Educação: análise de experiências em diferentes níveis de ensino. In: XXV Colóquio da AFIRSE, 2018, Lisboa, Portugal, Anais do XXV Colóquio da AFIRSE Portugal, Lisboa: Universidade de Lisboa, 2018. p. 699-709.

SOUZA, Severino; FRANCISCO, Ana. O Método da Cartografia em Pesquisa Qualitativa: Estabelecendo Princípios... Desenhando Caminhos... In: $5^{\circ}$ Congresso Ibero-Americano em investigação qualitativa: $\quad$ Porto, $\quad$ Portugal, 2016. Disponível em http://proceedings.ciaiq.org/index.php/ciaiq2016/article/viewFile/826/812. Acesso em 14 jan. 2020.

TELECO. Estatísticas de celulares no Brasil. [s. 1.]: Teleco, 2017. Disponível em http://www.teleco.com.br/ncel.asp. Acesso em 23 fev. 2020.

WE ARE SOCIAL AND HOOTSUITE. Digital in 2017: a study of Internet, social media, and mobile use throughout the region South America. [s. 1.: s. n.], 2017. 


\section{Informações da/o autora/autor}

Perla Maria Berwanger

Centro Universitário Estácio São Luís

E-mail: perla.berwanger@hotmail.com

ORCID: https://orcid.org/0000-0003-1143-9126

Link Lattes: http://lattes.cnpq.br/9714124867052671

João Batista Bottentuit Junior

Universidade Federal do Maranhão (UFMA)

E-mail:joaobbj@gmail.com

ORCID: https://orcid.org/0000-0002-4432-0271

Link Lattes: http://lattes.cnpq.br/4828197220419425 